\title{
THE WEAK TYPE INEQUALITY FOR THE MAXIMAL OPERATOR OF THE MARCINKIEWICZ-FEJÉR MEANS OF THE TWO-DIMENSIONAL WALSH-KACZMARZ SYSTEM
}

\author{
USHANGI GOGINAVA
}

Abstract. The main aim of this paper is to prove that the maximal operator $\sigma^{\#}$ of the Marcinkiewicz-Fejér means of the two-dimensional Fourier series with respect to the Walsh-Kaczmarz system is bounded from the martingale Hardy space $H_{1 / 2}$ to the space weak- $L_{1 / 2}$ and is not bounded from the martingale Hardy space $H_{1 / 2}$ to the space $L_{1 / 2}$ provided that the supremum in the maximal operator is taken over spatial indices. Mathematics subject classification (2000): 42C10.

Keywords and phrases: Walsh function, Hardy space, maximal operator.

\section{REFERENCES}

[1] G. GÁt, On $(C, 1)$ summability of integrable functions with respect to the Walsh-Kaczmarz system, Studia Math., 130 (1998), 135-148.

[2] G. Gát, U. Goginava, K. NAGY, On $\left(H_{p q}, L_{p q}\right)$-type inequality of maximal operator of Marcinkiewicz-Fejér means of double Fourier series with respect to the Kaczmarz system(English), J. Math. Inequal. Appl., 3, 9 (2006) 473-483.

[3] U. Goginava, The maximal operator of the Marcinkiewicz-Fejer means of the d-dimensional WalshFourier series, East J. Approx., 12 (2006), 295-302.

[4] J. MARCinkiewicZ, Sur une methode remarquable de sommation des series doublefes de Fourier, Ann. Scuola Norm. Sup. Pisa, 8 (1939), 149-160.

[5] K. NAGY, Some convergence properties of the Walsh-Kaczmarz system with respect to the Marczinkiewicz means, Rendiconti di Mathematica, 76 (2005), 503-516.

[6] F. SCHIPP, Pointwise convergence of expansions with respect to certain product systems, Analysis Math., 2 (1976), 63-75.

[7] P. Simon, On the Cesaro summability with respect to the Walsh-Kaczmarz system, J. Approx. Theory, 106 (2000), 249-261.

[8] V. A. Skvorcov, On Fourier series with respect to the Walsh-Kaczmarz system, Analysis Math., 7 (1981), 141-150.

[9] A. A. ŠNEIDER, On series with respect to the Walsh functions with monotone coefficients, Izv. Akad. Nauk SSSR Ser. Math., 12 (1948), 179-192.

[10] F. WEIsZ, Convergence of double Walsh-Fourier series and Hardy spaces, Approx. Theory and its Appl., 17 (2001), 32-44.

[11] F. WeISZ, Summability of multi-dimensional Fourier series and Hardy space, Kluwer Academic, Dordrecht, 2002.

[12] F. WeIsZ, $\vartheta$-summability of Fourier series, Acta Math. Hungar., 103, 1-2 (2004), 139-176.

[13] W. S. Young, On the a.e. convergence of Walsh-Kaczmarz-Fourier series, Proc. Amer. Math. Soc., 44 (1974), 353-358.

[14] L. V. Zhizhias viLI, Generalization of a theorem of Marcinkiewicz, Izv. Akad. Nauk USSR Ser Math., 32 (1968), 1112-1122. 